\title{
SCIENTIFIC PROGRAMME OF THE INTERNATIONAL GEOPHYSICAL YEAR 1957-58
}

\author{
By PRoF. SYDNEY CHAPMAN, F.R.S.
}

\section{Introduction}

$\mathrm{T}$ HE International Geophysical Year is the name associated with a forthcoming large-scale scientific study of the earth, now being planned and prepared. It will in our generation be the culmination of a long series of such efforts extending from the distant past. In the third century B.C., the Alexandrian natural philosopher Eratosthenes first measured the size of our globe. In A.D. 1600 William Gilbert's treatise on magnetism and electricity announced that the earth itself is a great magnet. Halley's undergraduate astronomical excursion to St. Helena in 1676 to observe the southern stars helped to lead him ten years later to produce the first extensive meteorological chart, of the trade winds. His magnetic voyages in the north and south Atlantic during 1698-1700 bore fruit in 1700 and 1701 by his publication of the first global magnetic charts. In the eighteenth century the French geodesists re-measured the globe by observations in Peru. Early in the nineteenth century Maury applied his studies of the winds to navigation by sailing vessels, and initiated world co-operation in maritime meteorology. Since the second half of that century, international scientific co-operation, particularly in geophysics and astronomy, has developed apace. The first and second International Polar Years of 1882-83 and 1932-33 were organized mainly for arctic observations of magnetism, meteorology and the aurora (the Second Polar Year only, not both First and Second as stated in Nature of January 8, p. 55, fell near sunspot minimum); in 1902-3 there was a concentration of scientific effort, on a smaller scale, in the Antarctic. 'The International Geophysical Year will be a fit successor to these earlier enterprises, far surpassing them in scope and intensity.

The Arctic, the Antarctic and the tropical belt, together with the meridians $70^{\circ}-80^{\circ}$ W., $10^{\circ}$ E., and $140^{\circ}$ E., will for the Geophysical Year programme as a whole be regions of specially intensive and com plete investigation. The meteorologists will add many other special regions for their part of the programme. The effort to be devoted to the Antarctic will be an outstanding feature of the enterprise; no less than twenty-one antarctic stations are planned, which should lead to a major advance in our knowledge of a part of the earth of which in some ways we know less than we do of the moon.

\section{Meteorology}

As in the two Polar Years, meteorology will be one of the main branches of the investigation. The range of observation will be global, not only or mainly arctic. In the first Polar Year the observations were made at the earth's surface; in the second Polar Year the atmosphere was explored in height as well as on the surface: the results were signalled by radio to the ground, thus obviating the need for recovering instrumental records from balloons the landfall of which could not be predicted. A major aim during 1957-58 will be to extend this exploration in height over a much greater part of the globe than hitherto, and to higher levels than beforo-especially in the tropics, where the troposphere is more than twice as deep (there approaching $20 \mathrm{~km}$.) as it is at the poles (about $8 \mathrm{~km}$.). At the standard meteorological stations the plan is to measure the height distribution of air temperature twice daily, and of wind four times daily, up to $20 \mathrm{~km}$., and wherever possible especially on the Regular World Days (three per month) - up to $30 \mathrm{~km}$.; on these days, when observations are to be specially intensive and widespread, the temperature observations are to be made four times daily.

The main objective will be to study the general circulation of the atmosphere, and the interchange of heat, momentum, angular momentum and entropy between the different parts of the globe. Hence the winds will be specially observed, by radio echoes from balloon-borne reflectors, and also by cloud observations from land and from ships at sea. The meteorological influence of the large-scale topography of the globe-the continents and oceans, and the great mountain chains and massifs-will be investigated. The familiar surface measurements of precipitation, and of air and surface (soil or water) temperatures, will be made more extensively, especially over the oceans; many small oceanic islands will be centres of scientific work of these and other kinds.

Besides the above fundamental measurements, the programme includes more widespread and extensive study of the atmospheric height distribution of ozone and water vapour; of solar and terrestrial radiation (including the albedo of the earth, as indicated by earth radiation reflected from the dark face of the moon); of the high 'mother of pearl' clouds and the far higher luminous night clouds; of thunderstorm regions over land and sea, by radio records of atmospherics; and of the chemical com. position of the air, for example, its oxygen and carbon dioxide content in the Antarctic. Rockets will extend the exploration of the atmosphere far above the heights attainable by meteorological balloons.

Under the guidance of the World Meteorological Organization, and with the co-operation of the International Association of Meteorology, instruments and methods of observation and publication will be standardized, and plans made for the handling and discussion of the immense mass of observations thus to be collected. The oceanographic programme of Geophysical Year observation will be an important supplement to the meteorological programme.

\section{Geomagnetism}

The chief geomagnetic problems to be solved are those relating to magnetic storms-long studied, but never with an adequate network of observatories. During 1957-58 the network of regular observatories will be enhanced, and be valuably strengthened by magnetic recorders installed at many ionospheric (and perhaps also cosmic ray) stations, for their own purpose of gaining early awareness of magnetic disturbance. The methods and instruments will be similar, in the main, to those used during 1932-33; 


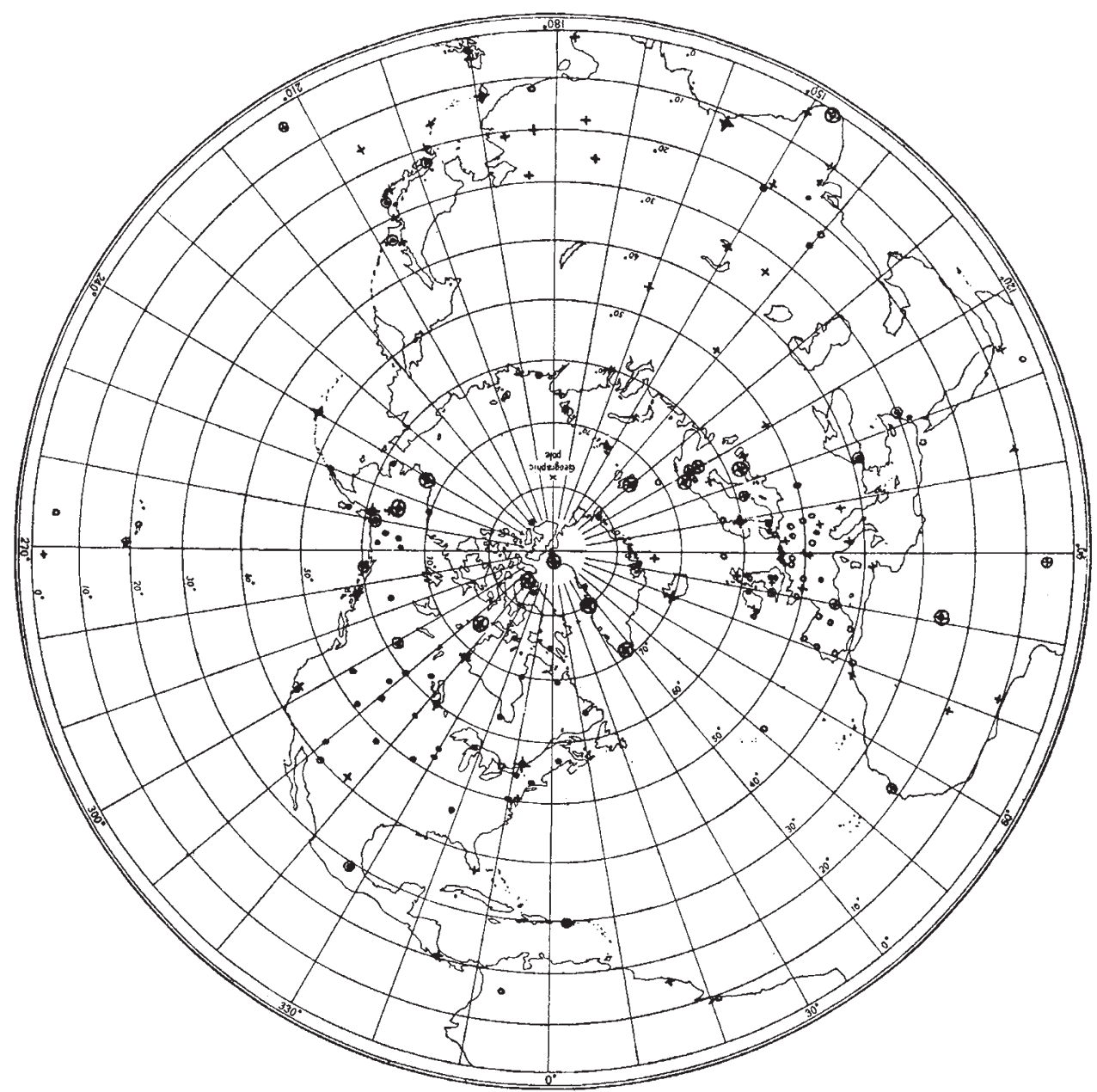

Fig. 1. Observation stations in the northern hemisphere for the International Geophysical Year : auroral stations, ; ionospheric stations, + ; magnetic observatories, $O$. The southern hemisphere will have fewer stations. Geomagnetic co-ordinates

but at some stations in or near the auroral zone the space gradients of the magnetic field will be measured, by setting up two satellite sets of recorders some miles distant, one to the north or south, the other to the east or west; these satellite stations, near enough to be managed by the staff at the main station, will, it is hoped, contribute materially to our knowledge of the intense systems of electric currents in the arctic ionosphere. These currents will also be explored in more detail, and closer at hand, though only for a few brief intervals of time, by magnetometers carried into or near them by rockets launched in high latitudes during magnetic storms.

Special care will be taken to avoid loss of record (such as occurred all too often in the past) during any very great magnetic storms that may befall during 1957-58.

The concentration of daytime electric current over or near the magnetic equator will be more fully observed by an increased number of tropical magnetic observatories.

Improved and more extensive recording of mag. netic pulsations, and also of earth currents, will be further important features of this part of the programme. As a contribution to the correlation of geomagnetic with other data, it is expected that indices of geomagnetic activity will be made available for each quarter-hour throughout the Geophysical Year, instead of, as now, for each three-hour interval.

\section{The Aurora}

The International Geophysical Year is too brief an interval to afford much improvement in the long: range statistics of auroral frequency; but it should mark a great advance in the observation of the many auroræ that may be expected to occur during the Year. In the regions where auroræ are often visible, at geomagnetic latitudes $60^{\circ}$ and more, there will be a network of auroral stations equipped with automatic cameras that will photograph the whole sky every five minutes throughout each night ; these will afford a synoptic view of the terrestrial extent and of the changes of auroræ never hitherto realizable. (Incidentally, this may also provide valuable data concerning cloud cover.) At some of these stations there will be automatic scanning spectrographs giving a succession of spectra of the euroral light in the vertical meridian plane, over nearly the whole arc from horizon to zenith to horizon. In rather lower geomagnetic latitudes, where auroræ are $l_{933}$ 
often visible, there will be a few stations similarly equipped; and there will be networks of visual observers, including some on sea as well as land, some equipped with angle-measuring devices, and with filters to isolate different spectral bands of the auroral light (thus cutting down the background sky light, especially during twilight and moonlight); some stations may have colorimeters designed to record the nature of the auroral light less elaborately than by spectrograph. Air pilots will take part in such visual observation, with special benefit when the sky is overcast. It is hoped that the network of careful visual observation will be extended into low latitudes, where the work should be much aided by the world system of warning of expected magnetic disturbance; professional, volunteer and other aid from meteorological and other organizations will especially be sought in these regions of lower latitude. A watch will be kept for the simultaneity of appearance of auroræ at the two ends, northern and southern, of a line or lines of geomagnetic force, or at pairs of stations in nearly the same geomagnetic longitude, and nearly equal northern and southern geomagnetic latitudes. The possibility of such observations is determined mainly by the availability of sites for fixed stations in high southern geomagnetic latitudes. For example, Macquarie Island $\left(54 \cdot 5^{\circ} \mathrm{S} ., 159 \cdot 0^{\circ} \mathrm{E}\right.$. geographic; $61 \cdot 1^{\circ} \mathrm{S}$. , $243 \cdot 1^{\circ}$ E. geomagnetic) could be paired with an Alaskan station to the south-west of College, Alaska; and Heard Island $\left(53 \cdot 0^{\circ}\right.$ S., $73 \cdot 4^{\circ}$ E.; $61 \cdot 2^{\circ}$ S., $129.9^{\circ}$ E.) could be paired with a north Siberian station. Means of intercommunication between such pairs of stations would be useful though not essential.

Some radio observatories will explore the auroral regions by short-wave beams echoed back to the station by suitably placed auroræ; by this means suroræe can be detected and located from a considerable distance, independent of cloud cover, and by day as well as by night. Any radio waves emitted from the aurora itself will also be registered.

Measurement of the increased scintillation and absorption of the radiation received from radio stars, when it passes through an auroral region, will be another and novel means of study of the enhanced ionospheric turbulence and ionospheric drifts associated with auroræ.

Special spectrographic studies will be made of the Doppler effect in the light of the hydrogen atoms which rush downward along the auroral rays and are scattered in all directions near the base of the rays. These or accompanying electrons will be detected and counted by ionization chambers borne by rockets launched from balloons.

\section{The Airglow and the Zodiacal Light}

All over the globe the upper atmosphere emits light, the airglow, which in general is too faint to be visible to the eye or to be photographed directly with short exposure; though sometimes patchy, it does not have the definite forms generally shown by the aurora. It is enhanced at twilight, and is observable also by day from rockets high above the atmospheric layers where the beam of solar radiation is scattered to give the general sky light. Its geographical distribution, changing with time of day and with season, will be investigated during the Geophysical Year, by means of scanning photoelectric photometers sensitive to four or more spectral bands of the radiation. These instruments, which automatically survey the entire sky each half-hour, will be disposed at intervals along a meridian chain, beginning at Thule, Greenland, and, crossing the auroral zone, extending through Canada, the United States and Mexico; others will be in Alaska, Hawaii and the Belgian Congo. Less complicated photometers, recording or visual, will be placed at further stations; the observations will necessarily measure, besides the intensity of the airglow, that of the auroral light, when present, and (in low latitudes) the zodiacal light. All these photometers will be carefully calibrated by astronomical methods or by the use of fluorescent surfaces activated by radioactive material of long life.

In addition, spectrographic and interferometric studies of the airglow will be made at a few special stations, and some high-level spectral observations will be made from rockets. Such studies will deal in detail with the various components of the spectrum of the airglow, its green and red atomic oxygen lines, the oxygen (and possibly nitrogen) bands, the yellow doublet of atomic sodium, and the strong infra-red and other radiations of the hydroxyl molecule $\mathrm{OH}$.

\section{Cosmic Rays}

As for the airglow, so also for cosmic rays, the Geophysical Year will be the first occasion on which a prolonged simultaneous standardized scheme of world-wide observation will be operated. Two main types of instrument will be used in this survey, one a counter telescope to record rays of relatively high energy, the other a neutron monitor for the lowenergy part of the cosmic-ray spectrum. The ionization-chamber counters already in operation at several stations should continue also throughout 1957-58. Detailed indications of the construction and operation of the two standard types of instrument will be made available in good time by the Geophysical Year Sub-Commission of the International Union of Pure and Applied Physics. It is hoped that the synoptic network will include sixty or more stations disposed in the special Geophysical Year areas (zones and meridians) and elsewhere; many of the instruments may be located at meteorological, magnetic or ionospheric stations.

As in other branches of the Geophysical Year work, plans will be prepared for standardized forms of recording the synoptic observations, for interchange of observations between stations, and for publication.

Additional special cosmic-ray investigations are planned, including moving photographic-emulsion records of the heavy-particle component, and highaltitude observations to determine the momentum spectrum, from mountain stations, aircraft, balloons and rockets. But the main emphasis of the cosmicray programme will be on the investigation of geomagnetic, aeronomic and solar problems to which cosmic-ray observations may be able to make a distinctive, perhaps unique, contribution.

The value of these observations will be greatly enhanced by the unprecedented array of solar and geophysical data available during the Geophysical Year.

\section{Solar Observations}

The Geophysical Year will be at or near a sunspot maximum which is expected to be of considerable but not exceptional intensity. Because so many geophysical phenomena are related to solar activicy, it is hoped that this will be continuously observed in the several different ways now possible. To this end, 
the observing hours at solar observatories will be extended in order to give an overlap of the periods of observation at stations in different longitudes, so that spells of cloudy weather at one or other station may not break the continuity of record. The longcontinued records of sunspot numbers, their positions and areas, of prominences and faculæ, will be supplemented by spectroscopic, spectrographic and photographic observations of solar flares, by spectrophotometric observations of the inner corona, and by records of solar radio emissions and their polarization, at a series of wave-lengths. Interferometric studies of the location of the radio sources will be made. Further, rocket spectra of sunlight at successive high altitudes will be photographed at intervals through. out the Geophysical Year.

Some solar observatories will equip themselves with recorders of atmospherics, which can give visual indication or audible warning of the beginning of solar flares, because of the improved propagation at such times. This will enable special observations to be made outside the normal 'solar patrol' periods.

The distribution of the line-of-sight component of the magnetic field of the sun will be mapped over the solar disk two or three times a day, by the Babcock method, at Mount Wilson and perhaps also at other solar observatories.

The solar observations during the Geophysical Year will be of cardinal importance to the scheme of world notification of Alerts and Special World Intervals, at times when magnetic, auroral, ionospheric and perhaps also cosmic-ray disturbances may be expected. Solar data as complete as possible will be vital for the detailed study of the sun's influence on magnetic, auroral, ionospheric, cosmic ray, and perhaps other data to be obtained during the Geophysical Year.

\section{lonospheric Investigations}

The pioneer arctic ionospheric investigations made during the second Polar Year were the most important extension of the programme of that enterprise, as compared with the programme of the first Polar Year. The fledgling of that epoch is now grown to be a major member of the Geophysical Year programme. More than a hundred stations for the exploration of the ionospheric layers overhead, by vertical beams of pulsed radiation, are expected to be in operation during the Geophysical Year; their distribution will in large part conform to the general plan of concentration along particular zones and meridians; but the considerable influence exerted on the ionosphere by the geomagnetic field will be taken into account by siting some stations with special reference to geomagnetic latitude, that is, to latitude relative to the axis of the main (dipole) component of the earth's field, with its north geomagnetic pole at $78 \cdot 6^{\circ} \mathrm{N} ., 70 \cdot 1^{\circ} \mathrm{W} .(1945)$.

This now standard method of ionospheric investigation, from fixed stations and also from aircraft, will enhance our knowledge of the complex and changing structure and disturbances of the ionosphere, from the equatorial to the auroral regions. In addition, many special studies will be made, In addition, many sper stations: of tropospheric propagation, of absorption, of ionospheric drift, of both back and forward scatter, of radio star scintillation, of atmospherics, of auroral and solar radio noise, of radio echoes from meteors and auroræ. There will also be direct exploration of the ionosphere, in situ, by rockets. The fulfilment of these plans should gather a rich harvest of aeronomic observations for study in association with solar, magnetic, auroral and airglow data. The ionospheric prediction stations in association with the solar observatories will play a vital part in the plan for World Alerts and Special World Intervals.

\section{Longitudes and Latitudes}

In the past there have been two world-wide determinations of the longitude differences between major astronomical observatories; the later one was in 1933. During the Geophysical Year, both the longitudes and latitudes, and the variations of these quantities, will be determined. This will lead to improved measurement of time, more precise determination of the irregularities of the earth's rotation, and corrections to star catalogues. The participating observatories will be those associated with the Bureau International de l'Heure, and, it is hoped, others newly organized and equipped, in areas where there are great gaps, especially near the equator and in the southern hemisphere. New types of fundamental instruments will be used.

In addition, a new method will be applied to determine the mutual relation of the geodetic networks covering the continents, by frequent photography of the moon against the background of stars, from about twenty well-distributed observatories; by this technique it is expected that the uncertainty of the extent of the oceanic gaps separating the networks will be reduced from 200-300 ft. to about $100 \mathrm{ft}$.

The availability of the great store of meteorological and ionospheric data to be obtained during 1957-58 will materially assist these undertakings.

\section{Glaciology}

The extent, character and behaviour of glaciers and snow cover will be measured in many parts of the world; this simultaneous survey will be far more geographically comprehensive than any made hitherto, and will be of great importance to meteorology and climatology. Apart from direct measurements at or from fixed stations, air reconnaissance will be used. Fixed survey points will be set up on selected glaciers in order that changes may be adequately determined by future comparison with later observations.

One great objective is to investigate the ice morphology and measure the total ice content of Antarctica. In this plan the co-operation of American, Australian, French and perhaps other nations is hoped for. It is anticipated that, with the aid of special aircraft, widespread seismic surveys will be made to determine the thickness of ice over the whole continent, and to settle the geography of the coast under the ice cover. This survey has special importance for the long-term climatological prediction of sea-level changes. The limits of permanent icea matter of present interest and valuable for comparison with future surveys-should be charted with considerable accuracy.

\section{Oceanography}

Many great problems of the oceans, especially in the southern hemisphere, await solution. Several ocean survey vessels belonging to the United States, Britain, West Germany and other nations will work on a co-ordinated plan during 1957-58. The water circulation, sediments and crustal structure will be 
studied along two meridians, and the measurements will include water velocities determined electromagnetically, and the heat exchange between sea and air, as well as the customary temperature, salinity and other standard measurements. About forty new stations will be set up, equipped with tide gauges and non-tidal long-wave recorders, on many islands and on some continental coasts. The shifting boundary between temperate and arctic waters, and the warming of the Arctic, will be studied. Continuous echo sounding, registration of magnetic intensity by towed instruments, collection of plankton by towed nets, radiocarbon sampling of the deeper waters, measurement of temperature gradients in sediments, collection of long sediment cores, and seismic reflexion observations will be among the activities of some of the oceanographical ships; these will also be available, so far as possible, as moving 'stations' for other types of geophysical observation.

\section{Seismic and Gravity Measurements}

The Geophysical Year will provide opportunity for seismic recording and gravity measurements to be made at many antarctic and island sites not ordinarily accessible or available, and it is expected that many expeditions will include such work in their programme.

\section{The Rocket Programme}

Rockets provide the most important new technical feature that distinguishes the Geophysical Year from the second Polar Year. They will enable the atmosphere to be explored over a much increased range of height in various ways, and may considerably extend our understanding of upper atmospheric processes and our knowledge of solar phenomena that affect the earth. The technical advances that are involved concern not only the rockets themselves, but also the measuring devices they carry. The measurement of atmospheric properties by instruments travelling at high speed presents difficult problems. During the past decade American scientists have made remarkable progress towards their solution, and the tide of invention in this field continues to flow strongly:

In most of the upper-atmospheric rocket researches thus far made, large and very expensive rockets have been used, launched from a desert site in New Mexico, with costly ground installations. The smaller rockets of this type can be, and have been, launched also from specially fitted ships. Recently, however, a much cheaper method of rocket exploration has been developed by Van Allen and his colleagues. The rocket is carried up to a considerable height by a large balloon, and launched at a predetermined pressure-level. The launching heights have ranged up to $27 \mathrm{~km}$., and the heights attained have at times exceeded $100 \mathrm{~km}$. The load that can be carried up to about $100 \mathrm{~km}$. is $15 \mathrm{kgm}$., which permits a wide variety of researches, such as those on cosmic rays, ozone, pressure, density and temperature, the solar spectrum, the sky brightness and airglow, geomagnetism, auroral particles, and ionospheric physics. The combined rocket-balloon system is called a 'rockoon'. Investigations are in progress into the vertical launching of rockets from aircraft, and if successful may contribute to the Geophysical Year programme.

The American National Committee for the Geophysical Year plans to fire approximately thirty-six large rockets ('Aerobees') and about a hundred rockoons, distributed throughout the period, and also geographically, from the Arctic to the Antaretic. Many of the above researches, if not all, will be included in the programme. The French National Committee plans to launch twelve of the large French rockets ('Véronique') from the Sahara, in pairs, at intervals; their instruments are expected to measure pressure and density, ionization, solar radiations, and particle masses (by mass-spectrograph). It is greatly hoped that other nations will also contribute to the rocket programme.

\section{Problems of Organization and Finance}

The achievement of the Geophysical Year will depend on the effort and funds devoted to it by the different participating nations. Naturally, their contributions will be unequal in magnitude and kind; help will be afforded by some nations to other nation-partners in the enterprise, by provision of instruments, training of observers, reduction of observations and in other ways. The unprecodented volume of observations that will accrue will present problems of collection and discussion for which detailed plans are not yet made. Many important points as to methods and recording of observations, and standardization and calibration of instruments, await settlement. Some important nations have still not associated themselves with the Geophysical Year. Thus there remains much scope for effort and thought in order to render the enterprise as successful as possible. But the stage already reached, more than two years before the Year begins, is good ground for confidence that the scheme will far surpass every previous co-operative scientific effort of its kind, and that it will lead to notable advances in knowledge of importance and interest to mankind. When the Geophysical Year ends, the level of activity in geophysical observation will necessarily drop rapidly and considerably; but past experience indicates that the subsequent level will still mark a distinct rise above the present level; thus it will afford a higher stage from which at some later epoch another International Geophysical Year can mount to yet greater heights and intensity.

\section{A PATTERN FOR INDUSTRIAL RESEARCH}

IN 1953, seven senior executives of the United Steel 1 Companies, Ltd., were invited to lecture to engineering undergraduates in the University of Cambridge on various aspects of industrial management. The lectures have now been presented in book form*, and among them is a valuable contribution to contemporary thinking about the organization and application of scientific research in industry by Dr. J. H. Chesters, assistant director of research to the Company.

The research worker in industry spends a good deal of time on development work that adds little to scientific knowledge; on the other hand, his best achievements are often based on fundamental data which he himself has collected or been able to appreciate and apply. * Industrial Management : a Course of Lectures given at Cam-
bridge University for the Faculty Board of Engineering. Pp. 124. (Sheffield: United Steel Companies, Ltd., 1954.) 